\title{
Numerical Simulation on Heat Recovery Efficiency of Different Working Fluids in High-Temperature Rock Mass
}

\author{
Xu Dong, ${ }^{1}$ Haozhe Geng $\mathbb{D}^{2}{ }^{2}$ Guan Hao, ${ }^{2}$ Pan $\mathrm{Li}^{3}$ Yi Teng, ${ }^{2}$ and Wen Zhang ${ }^{1}$ \\ ${ }^{1}$ School of Architecture Engineering, Xuzhou College of Industrial Technology, Xuzhou 221140, China \\ ${ }^{2}$ School of Mechanics and Civil Engineering, China University of Mining and Technology, Xuzhou 221116, China \\ ${ }^{3}$ School of Mechanics and Optoelectronics Physics, Anhui University of Science and Technology, Huainan, Anhui 232001, China
}

Correspondence should be addressed to Haozhe Geng; ts20030006a31@cumt.edu.cn

Received 25 May 2021; Revised 19 August 2021; Accepted 2 September 2021; Published 4 October 2021

Academic Editor: Zhiyuan Wang

Copyright (c) $2021 \mathrm{Xu}$ Dong et al. This is an open access article distributed under the Creative Commons Attribution License, which permits unrestricted use, distribution, and reproduction in any medium, provided the original work is properly cited.

It is of great significance for the sustainable development of global energy to develop hot dry rock (HDR) geothermal resources by using enhanced geothermal system (EGS) technology. Different working fluids in EGS have different heat recovery efficiencies. Therefore, this paper takes water and $\mathrm{CO}_{2}$ as the heat-carrying media and establishes a thermal hydraulic mechanical coupling model to simulate the heat recovery process in high-temperature rock mass. By considering the different confining pressures, rock temperature, and injection pressure, the advantages of $\mathrm{H}_{2} \mathrm{O}$-EGS and $\mathrm{CO}_{2}$-EGS are obtained. The results show that with the increase of confining pressure, the heat recovery efficiency of water is significantly higher than that of $\mathrm{CO}_{2}$, but at higher reservoir temperature, $\mathrm{CO}_{2}$ has more advantages as a heat-carrying medium. The net heat extraction rate will increase with the increase of injection pressure, which indicates that the mass flow rate plays a leading role in the heat recovery process and increases the injection pressure of fluid which is more conducive to the thermal recovery of EGS. This study will provide a technical guidance for thermal energy exploitation of hot dry rock under different geological conditions.

\section{Introduction}

The huge consumption of coal, oil, and other fossil fuels not only leads to energy crisis but also causes significant environmental and climate problems $[1,2]$. Therefore, the global efforts are to seek green and sustainable alternative energy. As a kind of low-carbon renewable energy, hot dry rock (HDR) geothermal resources have attracted worldwide attention in recent years [3-5]. In the process of developing hot dry rock, it is necessary to form a fracture network connecting injection well and production well by some means, such as hydraulic fracturing, so as to establish a "heat recovery and electricity generation" closed cycle-enhanced geothermal system, as shown in Figure $1[6,7]$.

Conventional EGS uses water as the heat-carrying medium, and there are a lot of researches on this technology at home and abroad [8-11]; it is found that the heat extraction of $\mathrm{H}_{2} \mathrm{O}$-EGS has great advantages in the presence of in situ fluid in the reservoir [12]. However, some scholars pointed out that the use of $\mathrm{H}_{2} \mathrm{O}$-EGS will cause a lot of water resource loss [13] and also cause a series of problems that are not conducive to the operation and maintenance of geothermal system [14-17]. To solve these problems, in 2000, Brown first proposed that it can use supercritical $\mathrm{CO}_{2}$ $\left(\mathrm{SCCO}_{2}\right)$ instead of water as a heat-carrying medium [18]. Since then, many studies have been carried out on the feasibility of using $\mathrm{CO}_{2}$ as heat extraction fluid [12, 14, 19-23]. In addition, many studies on the factors affecting the thermal extraction of $\mathrm{CO}_{2}$-EGS (such as $\mathrm{CO}_{2}$ injection rate, permeability, purity of $\mathrm{CO}_{2}$, and injection temperature of $\mathrm{CO}_{2}$ ) have been carried out [24-27]. $\mathrm{CO}_{2}$ has low density and viscosity, which can obtain large mobility ratio and buoyancy and reduce the pumping power in the heat recovery cycle $[18,28]$. However, low specific heat capacity of $\mathrm{CO}_{2}$ leads to lower effective energy of heat extraction than that of water, and the mass flow rate of $\mathrm{CO}_{2}$ is easily affected by reservoir temperature and pressure. At present, domestic and foreign experts and scholars have analyzed the influence of reservoir temperature, gas injection pressure, temperature, water injection temperature, and hot dry rock fracture 


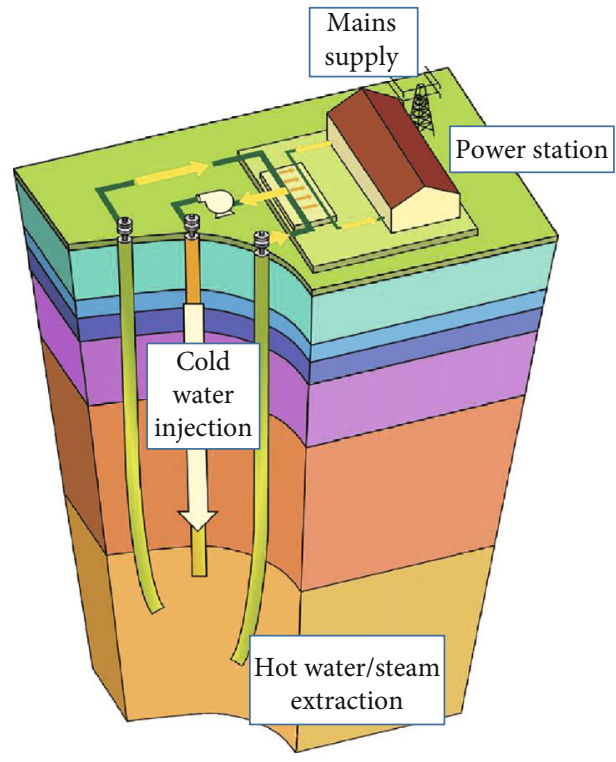

FIGURE 1: Simplified representation of EGS system.

morphology on $\mathrm{CO}_{2}$-EGS and $\mathrm{H}_{2} \mathrm{O}$-EGS through theoretical analysis and numerical simulation, but there is little research on the difference of thermal recovery efficiency of water injection and gas injection in high-temperature rock mass under the same conditions. Therefore, this paper will carry out relevant research on this issue.

This study focuses on the influence of the change of reservoir seepage field, reservoir temperature field, and reservoir stress field on the seepage and heat transfer of a heatcarrying medium, establishes a thermal-fluid-solid coupling model, and, respectively, analyzes the influence of injection pressure, sample temperature, and the change of confining pressure on the heat recovery efficiency when $\mathrm{H}_{2} \mathrm{O}$ and $\mathrm{CO}_{2}$ are used as working fluids. This study will provide technical guidance for improving hot dry rock productivity under different geological conditions.

\section{Governing Equations}

The coupling relationship among temperature field, seepage field, and stress field in geothermal exploitation is shown in Figure 2. The coupling of the three fields is realized by the seepage movement of the heat-carrying medium, the deformation of the fractured rock mass, and the heat transfer. Therefore, the first step is to determine the governing equations of each physical field.

2.1. Rock Deformation. The constitutive equation based on Biot's theory [29] is as follows:

$$
\varepsilon_{i j}=\frac{\sigma_{i j}}{2 G}-\frac{v}{2 G(1+v)} \sigma_{k k} \delta_{i j}+\frac{\alpha(1-2 v)}{2 G(1+v)} p_{f} \delta_{i j},
$$

where $\varepsilon_{i j}$ is the solid strain tensor component, $\sigma_{i j}$ is the stress tensor component, $p_{f}$ is the pore fluid pressure, $\sigma_{k k}$ is the normal stress component, $\alpha$ is the Biot coefficient of rock, $G$ is the shear modulus, and $v$ is the Poisson ratio.

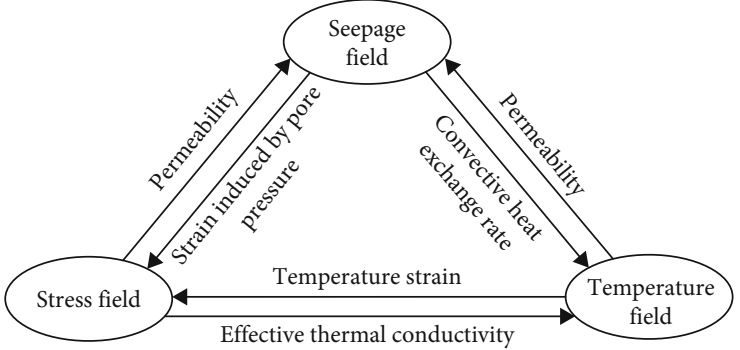

FIgURE 2: Thermal hydraulic mechanical coupling in geothermal exploitation.

According to Equation (1), the elastic constitutive equation of stress component is obtained as follows:

$$
\sigma_{i j}=2 G \varepsilon_{i j}-\frac{2 G}{1-2 v} \varepsilon_{k k} \delta_{i j}-\alpha p_{f} \delta_{i j}+\beta_{s} \Delta T_{s} \delta_{i j},
$$

where $\varepsilon_{k k}$ is the volumetric strain, $E$ is the elastic modulus, $\beta_{s}$ is the coefficient of thermal expansion of rock mass, and $T_{s}$ is the temperature of rock mass.

Relationship between strain and displacement under small deformation and deformation geometry equation is as follows:

$$
\varepsilon_{i j}=\frac{1}{2}\left(u_{i, j}+u_{j, i}\right)
$$

According to Terzaghi's [30] effective stress principle, the total stress of the reservoir is as follows:

$$
\sigma=\sigma^{\prime}-\mathbf{I} \alpha p_{f}
$$

where $\sigma$ is the total stress, $\sigma^{\prime}$ is the effective stress, and I is the equivalent tensor.

Without considering inertial force effect, the momentum conservation equation is as follows:

$$
\sigma_{i j, j}=-F_{i}
$$

Through combining Equations (2), (3), (4), and (5), the equilibrium differential equation expressed by displacement is obtained as follows:

$$
G \nabla^{2} u_{i}+(\lambda+G) u_{k, k i}-\alpha p_{f, i}-\frac{\beta_{s} E}{1-2 v} \Delta T_{s, i}+F_{i}=0
$$

where $u_{i}$ is the displacement component, $v$ is the Poisson ratio, $F_{i}$ is the volume force component, and $\lambda$ is the lame elastic constant.

2.2. Fluid Flow. This study is based on the geothermal reservoir dominated by tight crystalline rocks such as granite. Here, only the fluid flow in fractures is considered. Fluid flow in the fracture is a saturated single-phase flow process, and the mass conservation equation of fluid flow is 

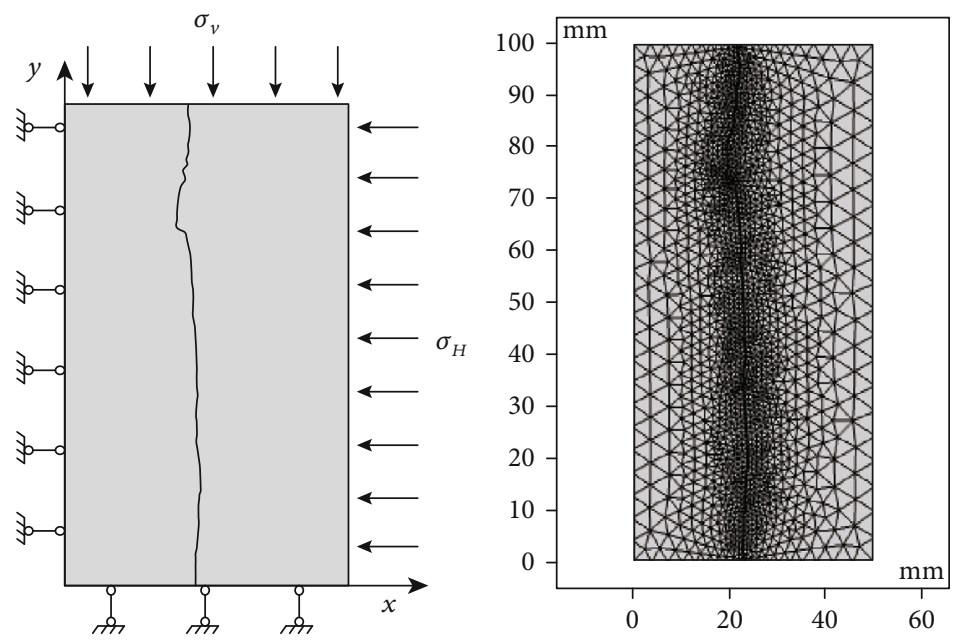

FIGURE 3: Geometric model.

TABLE 1: Relevant parameters in the model.

\begin{tabular}{lcc}
\hline Parameter & Value & Unit \\
\hline The density of sample $\left(\rho_{s}\right)$ & 2700 & $\mathrm{~kg} / \mathrm{m}^{3}$ \\
Dynamic viscosity of $\mathrm{CO}_{2}\left(\mu_{g}\right)$ & $9.3832 \times 10^{-5}$ & $\mathrm{~Pa} \cdot \mathrm{s}$ \\
Universal gas constant $(R)$ & 8.314510 & $\mathrm{~J} /(\mathrm{mol} \cdot \mathrm{K})$ \\
Molar mass of $\mathrm{CO}_{2}(M)$ & 44.009 & $\mathrm{~g} / \mathrm{mol}$ \\
Thermal conductivity of $\mathrm{CO}_{2}\left(\kappa_{g}\right)$ & 0.109 & $\mathrm{~W} /(\mathrm{m} \cdot \mathrm{K})$ \\
Thermal conductivity of rock sample $\left(\kappa_{s}\right)$ & 2.1 & $\mathrm{~W} /(\mathrm{m} \cdot \mathrm{K})$ \\
Specific heat capacity of $\mathrm{CO}_{2}\left(C_{p g}\right)$ & 1955.6 & $\mathrm{~J} /(\mathrm{kg} \cdot \mathrm{K})$ \\
Specific heat capacity of rock sample $\left(C_{p s}\right)$ & $\mathrm{J} /(\mathrm{kg} \cdot \mathrm{K})$ \\
Porosity $(\phi)$ & 020 & $\mathrm{~m}{ }^{2}$ \\
Permeability $(k)$ & $3.94 \times 10^{-15}$ & $\mathrm{GPa}$ \\
Elastic modulus $(E)$ & 37.5 & $\mathrm{~mm}$ \\
Poisson ratio $(v)$ & 0.25 & $\mathrm{~kg} / \mathrm{m}^{3}$ \\
Fracture aperture $(w)$ & 0.1 & $\mathrm{~Pa} \cdot \mathrm{s}$ \\
Density of water $\left(\rho_{w}\right)$ & 1000 & $\mathrm{~W} /\left(\mathrm{m}^{3} \cdot \mathrm{K}\right)$ \\
Dynamic viscosity of water $\left(\mu_{w}\right)$ & 0.001 & 2 \\
Convection heat exchange coefficient $\left(h_{s f}\right)$ & &
\end{tabular}

expressed by the following formula:

$$
\frac{\partial\left(\rho_{f} \varphi\right)}{\partial t}-\nabla\left(\rho_{f} \frac{k}{\mu} \nabla p_{f}\right)=Q_{f}
$$

where $\rho_{f}$ is the fluid density, $Q_{f}$ is the source (sink) term of the fluid, $\mu$ is the dynamic viscosity of the fluid, $p_{f}$ is the fluid pressure, $\varphi$ is the porosity, and $k$ is the permeability.
Considering the roughness of fracture, the permeability of fluid in fracture is as follows [31]:

$$
k=\frac{b^{2}}{12 f},
$$

where $f$ is the roughness coefficient of fracture, $f=1+17$ $(a / 2 b)^{1.5}$

Under the influence of pore pressure and thermal stress, the fracture width is as follows [32]:

$$
b=b_{0} e^{-\sigma_{n} / K_{n}}
$$


TABLE 2: Simulation scheme.

\begin{tabular}{|c|c|c|c|c|c|c|c|}
\hline Number & $\begin{array}{l}\text { Working } \\
\text { fluids }\end{array}$ & $\begin{array}{l}\text { Influence } \\
\text { factor }\end{array}$ & $\begin{array}{c}\text { Axial } \\
\text { compression } \\
(\mathrm{MPa})\end{array}$ & $\begin{array}{c}\text { Confining } \\
\text { pressure }(\mathrm{MPa})\end{array}$ & $\begin{array}{c}\text { Injection } \\
\text { pressure }(\mathrm{MPa})\end{array}$ & $\begin{array}{l}\text { Boundary heat source } \\
\qquad\left(\mathrm{W} / \mathrm{mm}^{2}\right)\end{array}$ & $\begin{array}{c}\text { Initial } \\
\text { temperature }(\mathrm{K})\end{array}$ \\
\hline 1 & \multirow{3}{*}{$\begin{array}{l}\text { Water/ } \\
\mathrm{CO}_{2}\end{array}$} & $\begin{array}{l}\text { Confining } \\
\text { pressure }\end{array}$ & 35 & $26 / 28 / 30 / 35$ & 2 & 0.001 & 473 \\
\hline 2 & & $\begin{array}{c}\text { Initial } \\
\text { temperature }\end{array}$ & 35 & 26 & 2 & 0.001 & $\begin{array}{c}373 / 403 / 433 / \\
493\end{array}$ \\
\hline 3 & & $\begin{array}{l}\text { Injection } \\
\text { pressure }\end{array}$ & 35 & 26 & $8 / 9 / 10 / 11$ & 0.001 & 473 \\
\hline
\end{tabular}

where $\sigma_{n}$ is the normal stress and $K_{n}$ is the normal stiffness of the crack.

The change of porosity under the influence of stress field, seepage field, and temperature field is as follows:

$$
\begin{aligned}
\varphi-\varphi_{0}= & \left(\frac{1-\varphi_{0}}{3 K}-\frac{1}{3 K_{s}}\right)\left(\sigma_{k k}+3 p_{f}\right)-\varphi_{0}\left(\frac{1}{K_{s}^{*}}-\frac{1}{K_{s}}\right) p_{f} \\
& +\varphi_{0}\left(1-\varphi_{0}\right)\left(\beta_{p}-\beta_{s}\right) \Delta T_{s} .
\end{aligned}
$$

2.3. Heat Transfer. The heat transfer process in fractured rock mass can be expressed by the following formula:

$$
\begin{aligned}
& \frac{\partial T_{s}}{d t}\left(\rho_{f} C_{p g}\right)_{\mathrm{eff}}+\nabla\left(\rho_{f} C_{p f} \mathbf{u} T_{s}\right)-\nabla \mathbf{q}=Q_{T}, \\
& \mathbf{q}=-\kappa_{\mathrm{eff}} \nabla T_{s}, \\
&\left(\rho_{f} c_{p f}\right)_{\mathrm{eff}}=(1-\varphi) \rho_{s} C_{p s}+\varphi \rho_{f} C_{p g}, \\
& \kappa_{\mathrm{eff}}=(1-\varphi) \kappa_{s}+\varphi \kappa_{g},
\end{aligned}
$$

where $T_{s}$ is the temperature of the rock sample, $\rho_{f}$ is the density of the fluid, $C_{p g}$ is the specific heat of the fluid, $\mathbf{u}$ is the flow velocity, $Q_{T}$ is the source term, $\mathbf{q}$ is the heat conduction flux, $\kappa_{\text {eff }}$ is the effective thermal conductivity, $\phi$ is the porosity, $\rho_{s}$ is the density of the rock sample, $\kappa_{s}$ is the thermal conductivity of rock sample, and $\kappa_{g}$ is the thermal conductivity of fluid.

\section{Numerical Model and Simulation Scheme}

3.1. Model Description. Previous laboratory tests have studied the thermal recovery efficiency of alternating injection of $\mathrm{H}_{2} \mathrm{O}$ and $\mathrm{CO}_{2}$ into standard granite samples with single fracture; combined with the experimental results of $\mathrm{H}_{2} \mathrm{O}$ $\mathrm{SCCO}_{2}$ alternate injection, the model of rock seepage heat extraction under THM coupling is established [33]. Therefore, the size of the model is consistent with the standard rock sample $(50 \times 100 \mathrm{~mm})$, and there is a thorough crack in the axial direction of the model; the geometric model is shown in Figure 3. It contains 3324 free triangle units, the minimum unit size is $1 \mathrm{~mm}$, and the maximum unit size is $6 \mathrm{~mm}$. The finite element software COMSOL Multiphysics is used to solve the problem. The solving module includes

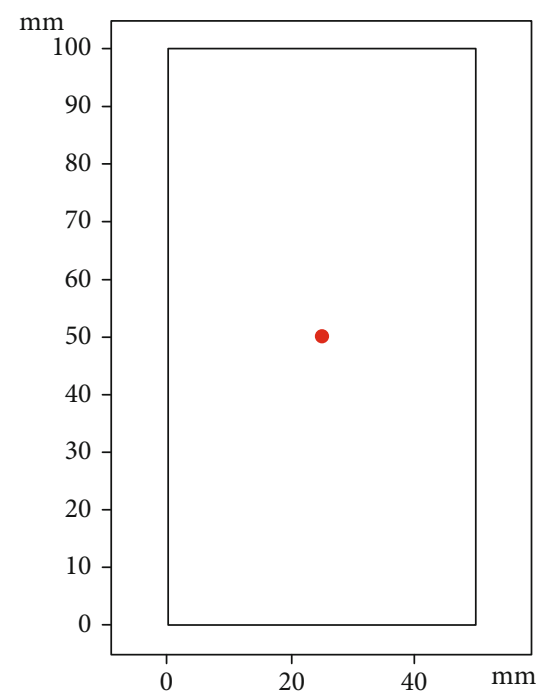

FIGURE 4: Select measuring point position.

structural mechanic module, groundwater flow module, and heat transfer module.

3.2. Initial and Boundary Conditions. The boundary conditions of stress field include the following: the upper boundary applies axial force, the right boundary applies lateral force, and the left and lower boundaries apply roller support.

Boundary conditions of temperature field include the following: the upper boundary applies axial force, the right boundary applies lateral force, and the left and lower boundaries apply roller support.

Boundary conditions of seepage field include the following: the upper boundary and the lower boundary are constant pressure boundaries, and the left boundary and right boundary are both zero flux boundaries.

After reading the relevant literature [34, 35], the thermophysical parameters of $\mathrm{CO}_{2}$ and other fluids are determined, and the relevant parameters in the model are shown in Table 1.

3.3. Simulation Scheme and Data Process. The simulation scheme is shown in Table 2.

The measuring points $(25 \mathrm{~mm}$ and $50 \mathrm{~mm})$ selected in the model are shown in Figure 4.

The heat energy of heat-carrying fluid is the product of instantaneous sensible enthalpy and mass flow rate, and 


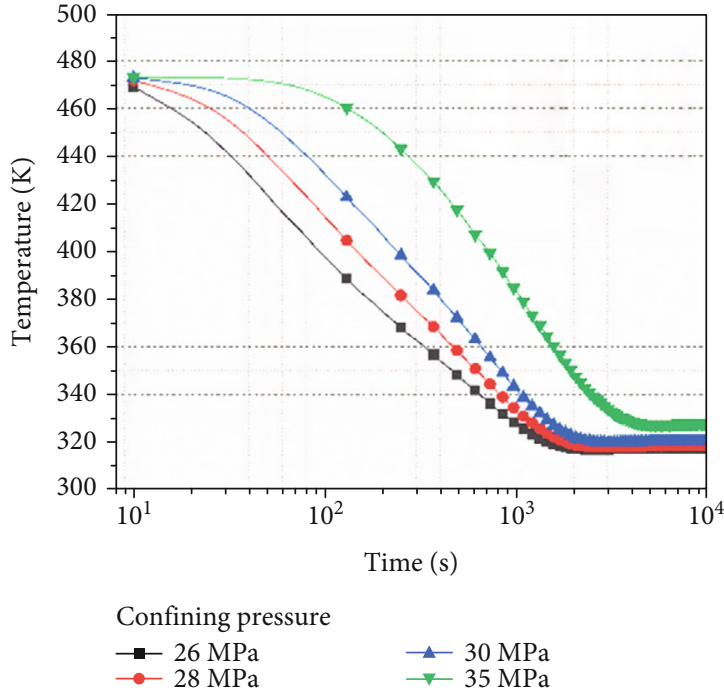

(a)

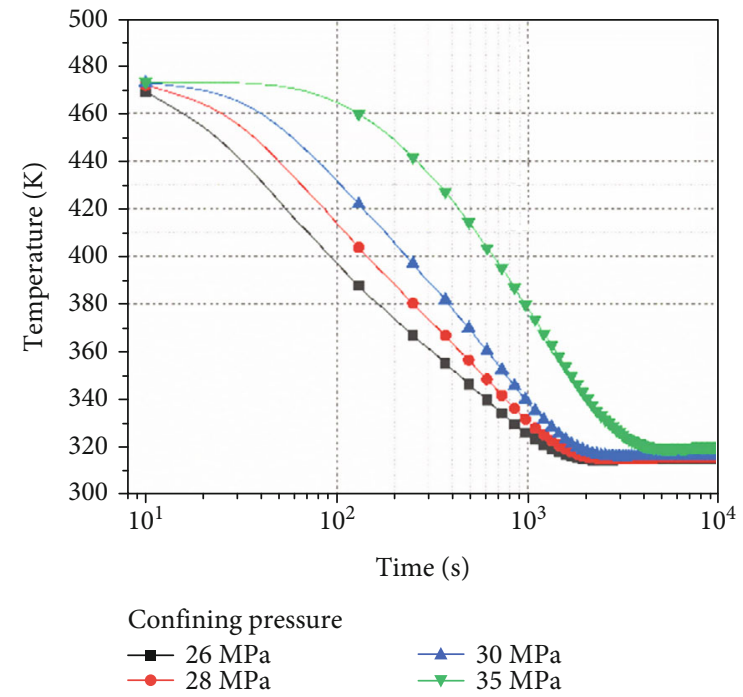

(b)

FIGURE 5: Change of temperature at measuring point with injection time. (a) Thermal recovery by water injection. (b) Thermal recovery by $\mathrm{CO}_{2}$ injection.

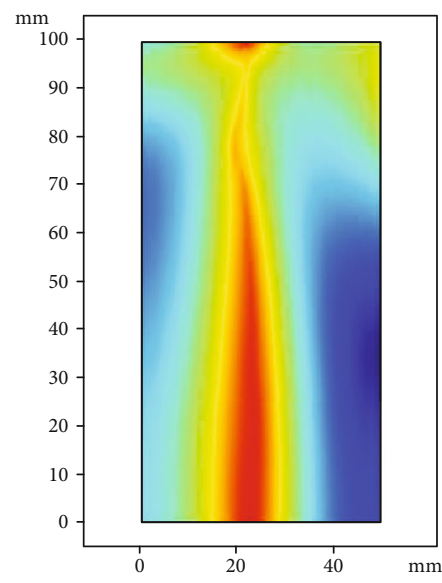

(a) $26 \mathrm{MPa}$

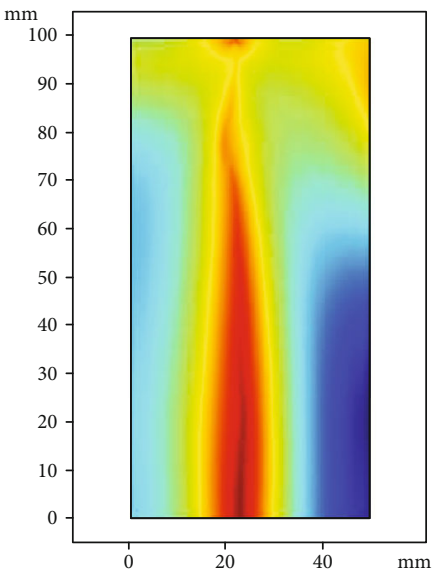

(b) $28 \mathrm{MPa}$

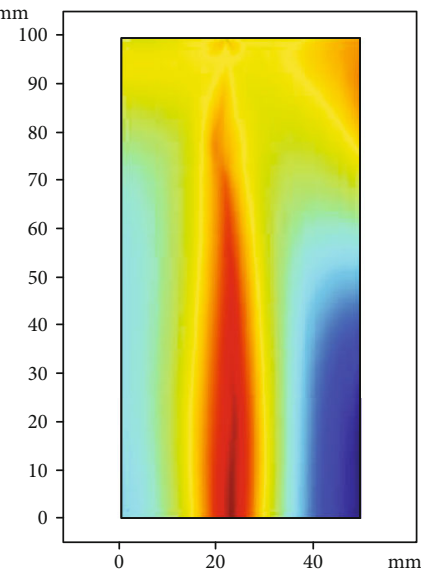

(c) $30 \mathrm{MPa}$

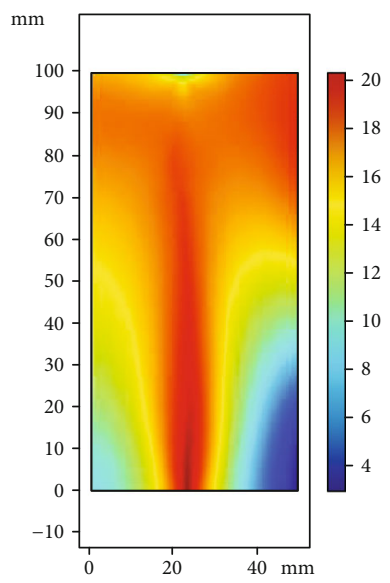

(d) $35 \mathrm{MPa}$

Figure 6: Stress distribution after $600 \mathrm{~s} \mathrm{CO}_{2}$ injection under different confining pressures.

the net heat productivity of the production well is as follows:

$$
E=Q_{\text {out }}(t) h_{\text {out }}(t)-Q_{\text {in }}(t) h_{\text {in }}(t)
$$

where $E$ is the heat energy extracted by the heat-carrying fluid, $Q_{\text {out }}$ is the mass flow rate of the heat-carrying fluid flowing out of the rock mass $(\mathrm{kg} / \mathrm{s}), Q_{\text {in }}$ is the mass flow rate of the heat-carrying fluid flowing into the rock mass $(\mathrm{kg} / \mathrm{s})$, $h_{\text {out }}$ is the specific enthalpy of the fluid at the injection end $(\mathrm{J} / \mathrm{kg})$, and $h_{\text {in }}$ is the specific enthalpy of the fluid at the outflow end $(\mathrm{J} / \mathrm{kg})$.

\section{Results and Discussions}

4.1. Effect of Confining Pressure. In the simulation of the influencing factors of confining pressure, the initial temper- ature of the model is $473 \mathrm{~K}$, and the boundary heat source is $0.001 \mathrm{~W} / \mathrm{mm}^{2}$. The fluid injection pressure is $2 \mathrm{MPa}$, the axial pressure is $35 \mathrm{MPa}$, and the confining pressure is $26 \mathrm{MPa}, 28 \mathrm{MPa}, 30 \mathrm{MPa}$, and $35 \mathrm{MPa}$, respectively. After, respectively, injecting water and $\mathrm{CO}_{2}$ under different confining pressures, the temperature change at the measuring point is shown in Figure 5.

The results show that the temperature at the measuring point increases with the increase of confining pressure after water injection (or $\mathrm{CO}_{2}$ ), and there are three stages of temperature change: initial stable stage (short time), rapid decrease stage, and final stable stage. When the confining pressure is low, the first stage is not obvious. With the increase of confining pressure, the duration of the initial stable stage is prolonged, and the start of the second stage is delayed. In the third stage, the higher the confining pressure, 


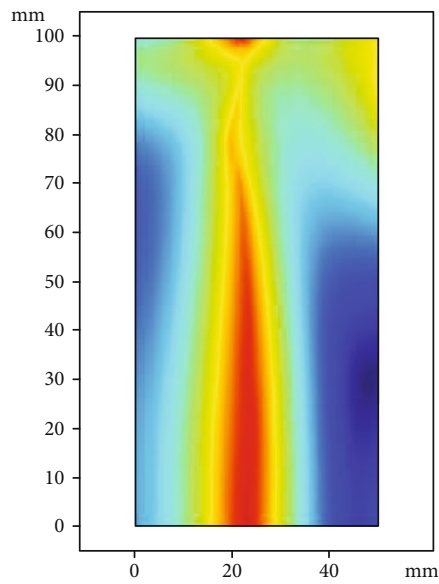

(a) $26 \mathrm{MPa}$

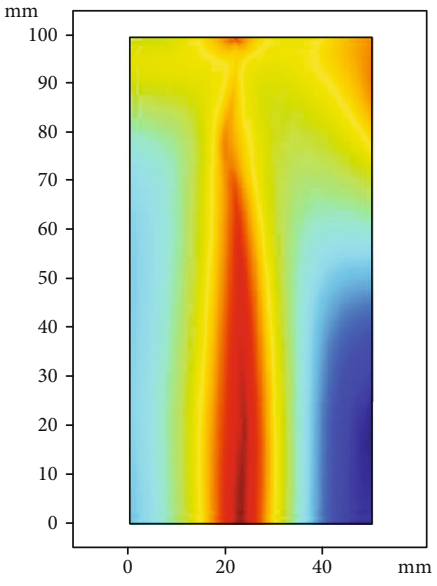

(b) $28 \mathrm{MPa}$

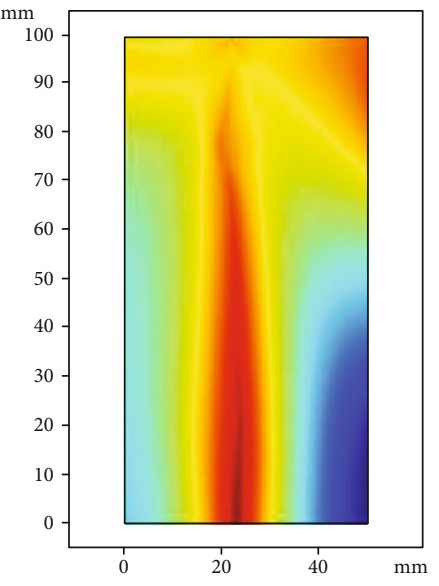

(c) $30 \mathrm{MPa}$

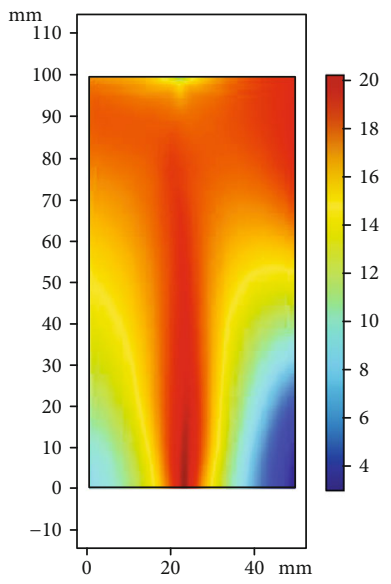

(d) $35 \mathrm{MPa}$

FIGURE 7: Stress distribution after $600 \mathrm{~s}$ water injection under different confining pressures.

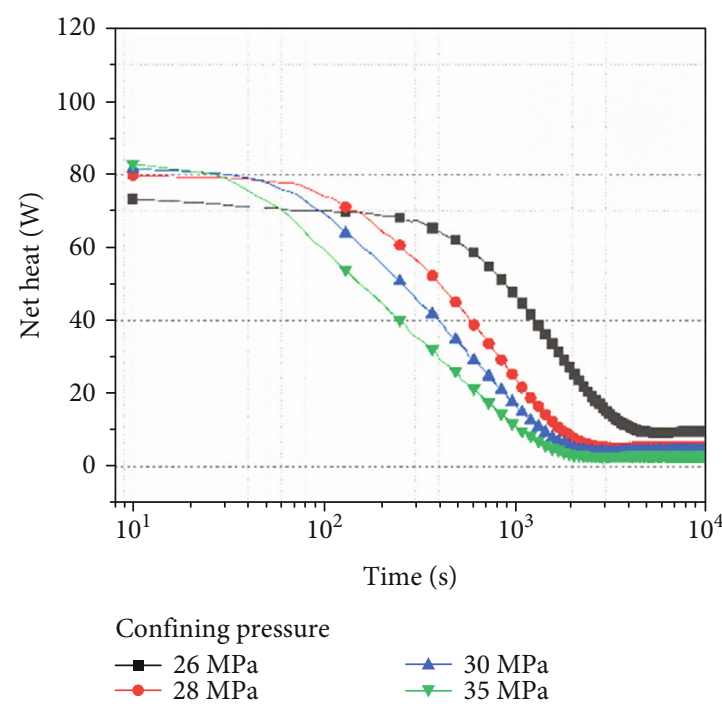

(a)

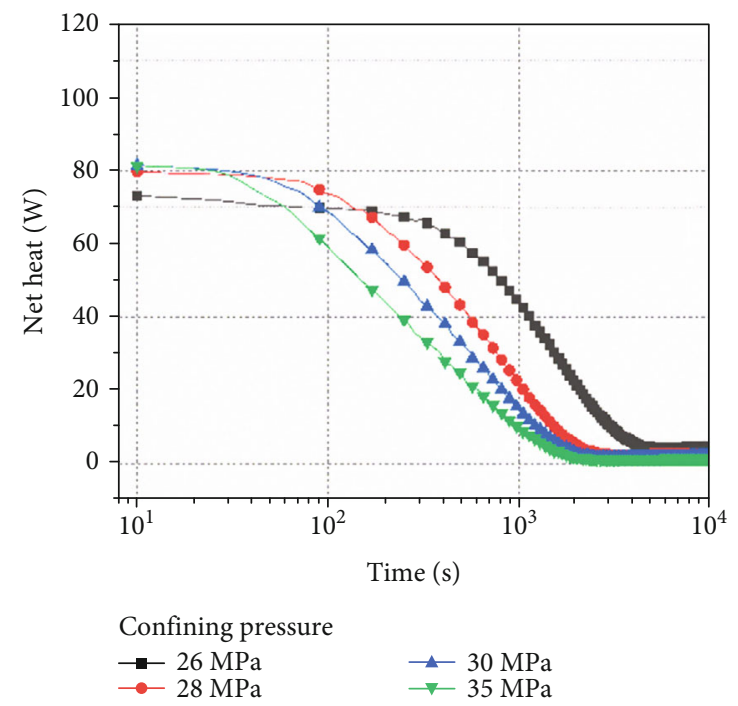

(b)

Figure 8: Variation of net heat with injection time under different confining pressures. (a) Thermal recovery by water injection. (b) Thermal recovery by $\mathrm{CO}_{2}$ injection.

the higher the temperature is when the pressure is stable. Comparing the temperature after water injection and the temperature after $\mathrm{CO}_{2}$ injection, it is found that the temperature at the measuring point after water injection is slightly higher than that after $\mathrm{CO}_{2}$ injection, especially under the confining pressure of $35 \mathrm{MPa}$, the temperature difference between the two conditions in the third stage at the measuring point is about $10 \mathrm{~K}$.

Figures 6 and 7 show the stress distribution of rock samples after $600 \mathrm{~s}$ water injection and $600 \mathrm{~s} \mathrm{CO}_{2}$ injection under 26-35 MPa confining pressure, respectively. It can be seen that when the confining pressure increases, the internal stress of the model increases. According to Equation (9), the model fracture opening decreases with the increase of stress, which reduces the permeability and affects the heat recovery efficiency.
Figure 8 shows the change of net heat with time after water and $\mathrm{CO}_{2}$ injection under different confining pressures. It can be seen that the net heat decreases with the increase of confining pressure in the process of water injection and $\mathrm{CO}_{2}$ injection. Increasing confining pressure reduces fluid velocity, prolongs heat exchange time between fluid and rock mass, but also reduces permeability and fluid mass flux in corresponding time; under the combined influence of the two factors, the net heat decreased, indicating that the latter factor had a greater influence. Comparing with the previous experimental research, the results are generally consistent with the experimental results [36].

Comparing the net heat results after water injection and $\mathrm{CO}_{2}$ injection, it is found that the net heat extracted after water injection is slightly higher than that of $\mathrm{CO}_{2}$ injection 


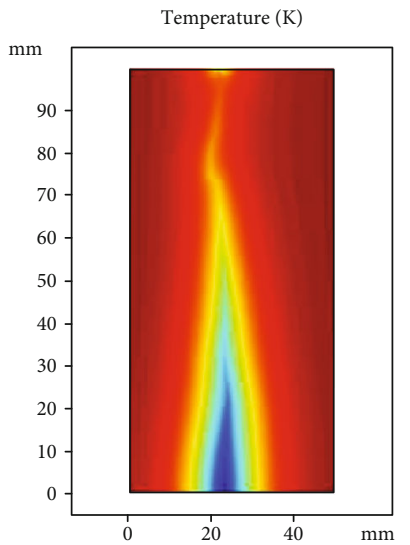

(a) $26 \mathrm{MPa}$ confining

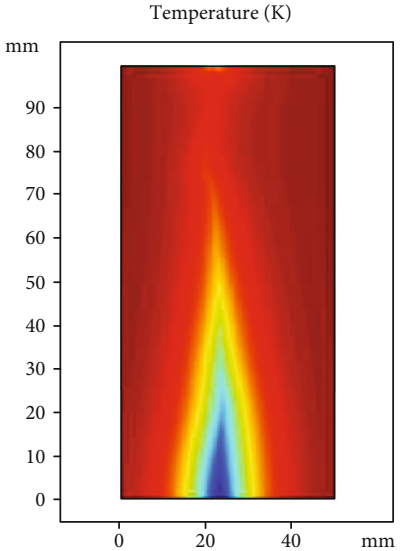

(b) $28 \mathrm{MPa}$ confining

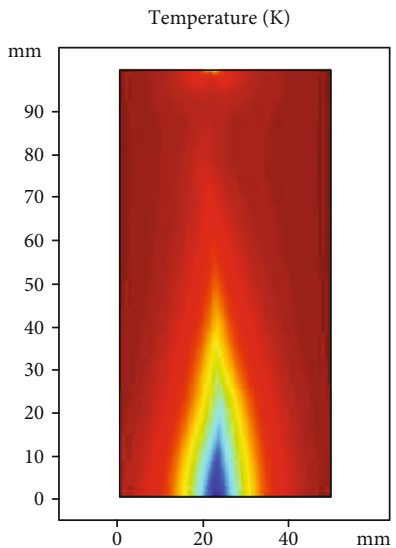

(c) $30 \mathrm{MPa}$ confining

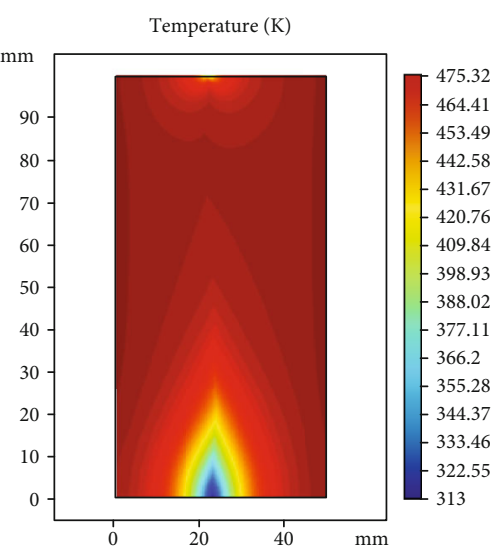

(d) $35 \mathrm{MPa}$ confining

Figure 9: Temperature distribution after $600 \mathrm{~s}$ water injection under different confining pressures.

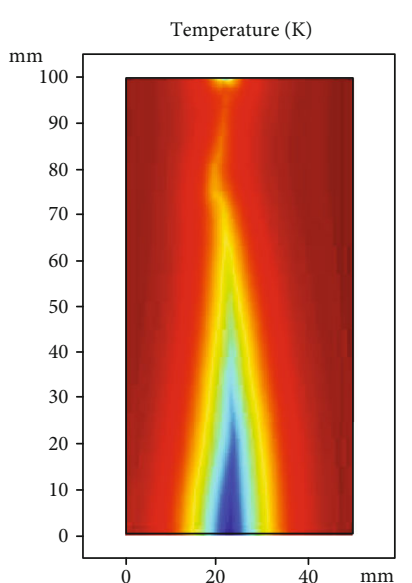

(a) $26 \mathrm{MPa}$ confining

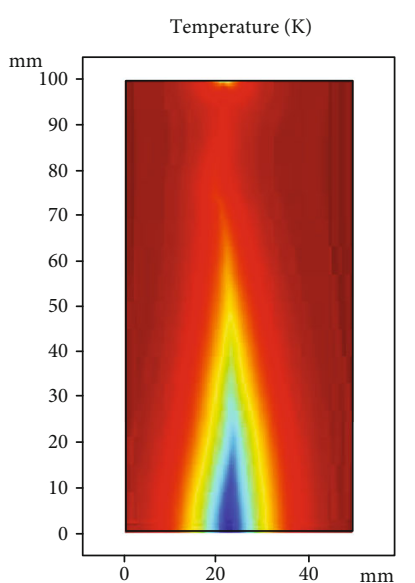

(b) $28 \mathrm{MPa}$ confining

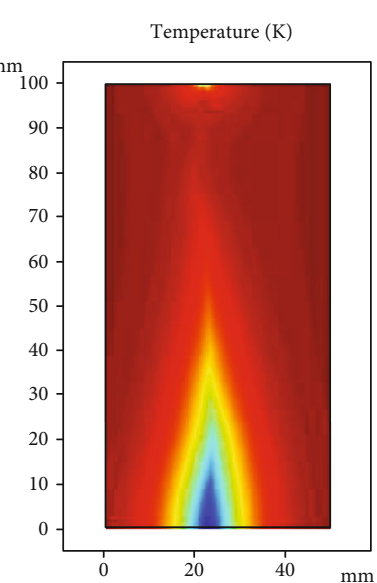

(c) $30 \mathrm{MPa}$ confining

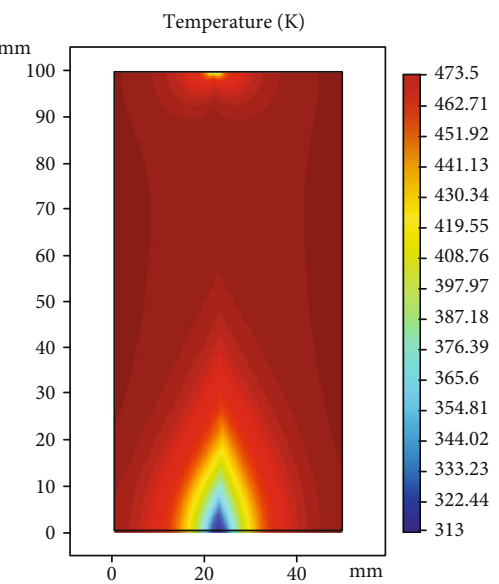

(d) $35 \mathrm{MPa}$ confining

FIgURE 10: Temperature distribution after $600 \mathrm{~s} \mathrm{CO}_{2}$ injection under different confining pressures.

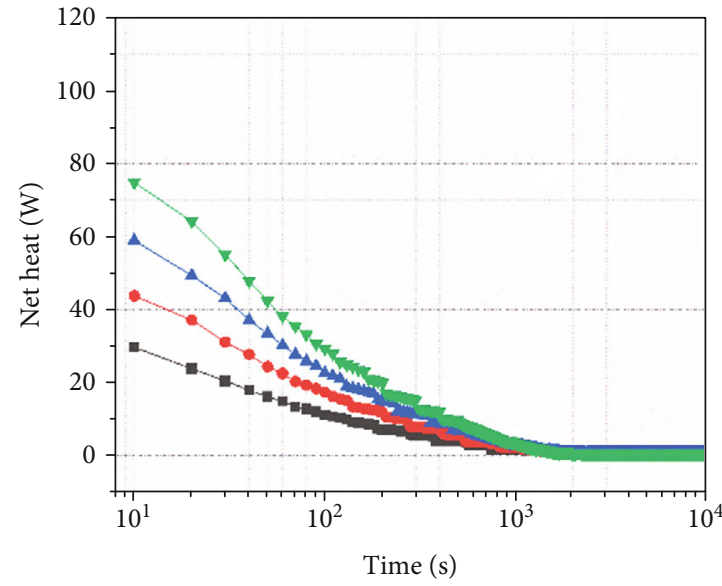

Initial sample temperature

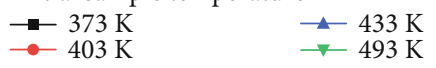

(a)

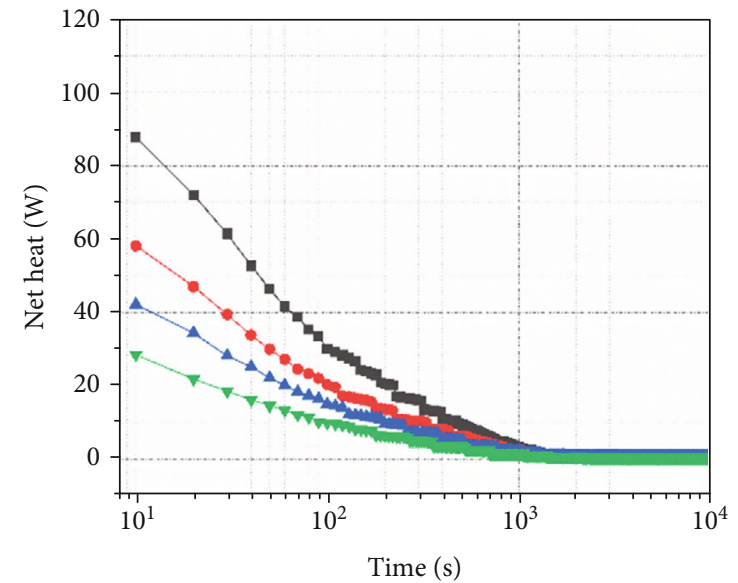

Initial sample temperature

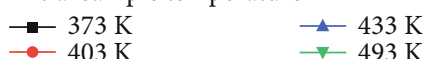

(b)

Figure 11: Variation of net heat with injection time at different initial temperatures. (a) Thermal recovery by water injection. (b) Thermal recovery by $\mathrm{CO}_{2}$ injection. 


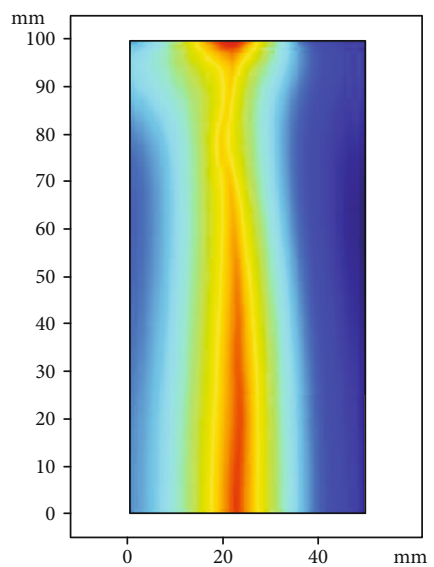

(a) $373 \mathrm{~K}$

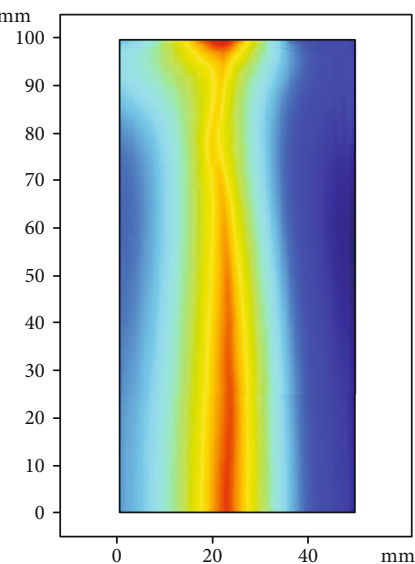

(b) $403 \mathrm{~K}$

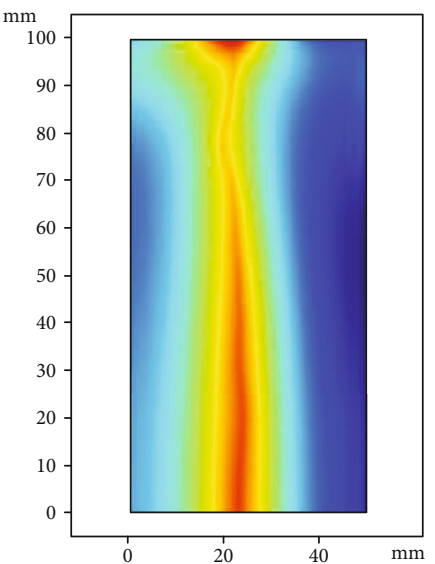

(c) $433 \mathrm{~K}$

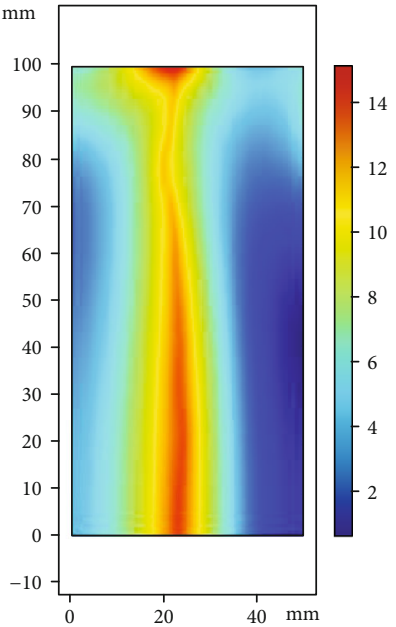

(d) $493 \mathrm{~K}$

FIGURE 12: Stress distribution after $600 \mathrm{~s} \mathrm{CO}_{2}$ injection under different initial temperatures.

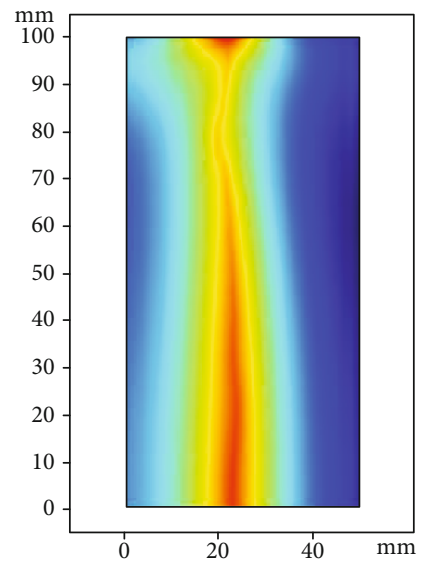

(a) $373 \mathrm{~K}$

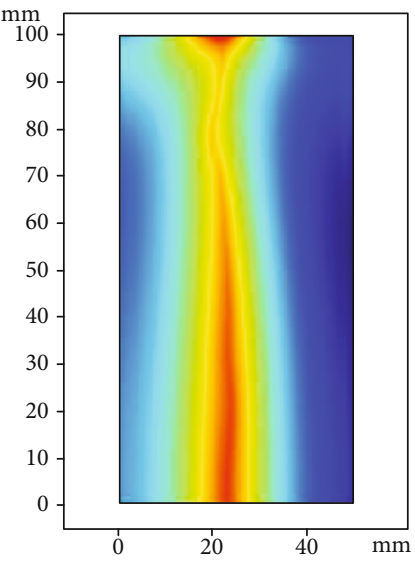

(b) $403 \mathrm{~K}$

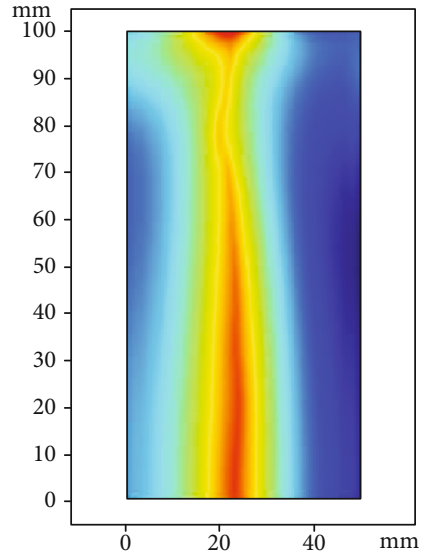

(c) $433 \mathrm{~K}$

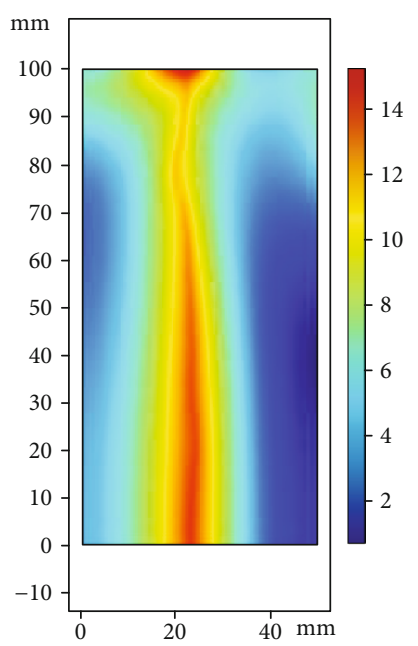

(d) $493 \mathrm{~K}$

FIGURE 13: Stress distribution after $600 \mathrm{~s}$ water injection under different initial temperatures.

under the same confining pressure. This difference is not obvious under low confining pressure, but with the increase of confining pressure, the heat recovery efficiency of water is significantly higher than that of $\mathrm{CO}_{2}$.

Figures 9 and 10, respectively, show the temperature distribution of rock samples after water injection for $600 \mathrm{~s}$ and $\mathrm{CO}_{2}$ injection for $600 \mathrm{~s}$ under confining pressure of 26$35 \mathrm{MPa}$. It can be seen that the heat loss of rock sample under low confining pressure is obviously lower than that under high confining pressure, and the heat loss of rock sample after water injection is slightly lower than that of $\mathrm{CO}_{2}$ injection under the same confining pressure. It can be seen that the thermophysical properties of fluid have an obvious effect on the heat recovery rate. Although the low mass flow rate of $\mathrm{CO}_{2}$ leads to lower thermal recovery under the same conditions, the heat loss of rock samples by $\mathrm{CO}_{2}$ is higher than that by water.
4.2. Effect of Initial Temperature. In the simulation of the influence factors of initial temperature of rock sample, boundary heat source is $0.001 \mathrm{~W} / \mathrm{mm}^{2}$, fluid injection pressure is $2 \mathrm{MPa}$, axial compression is $35 \mathrm{MPa}$, and the confining pressure is $26 \mathrm{MPa}$. We simulated the thermal recovery process of water injection and $\mathrm{CO}_{2}$ injection at the initial temperature of $373 \mathrm{~K}, 403 \mathrm{~K}, 433 \mathrm{~K}$, and $493 \mathrm{~K}$, respectively. Figure 11 shows the rule of net heat variation with water and $\mathrm{CO}_{2}$ injection time at different temperatures.

It can be seen that in the process of water injection heat recovery, the net heat increases with the increase of the initial temperature of the rock sample. In the process of $\mathrm{CO}_{2}$ injection heat recovery, the net heat decreases with the increase of initial temperature of rock sample. Comparing with the previous experimental research, the results are generally consistent with the experimental results [37]. Due to the small size of rock sample, the temperature of 


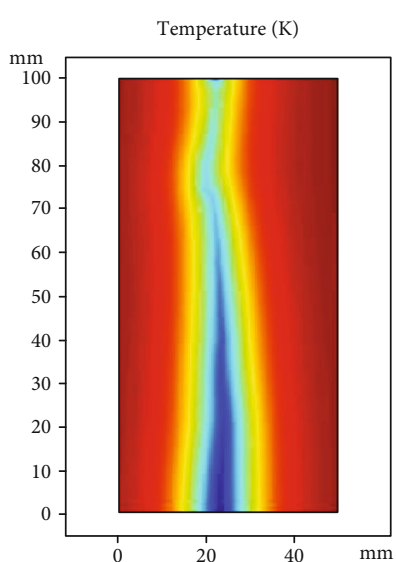

(a) Water injection at $373 \mathrm{~K}$

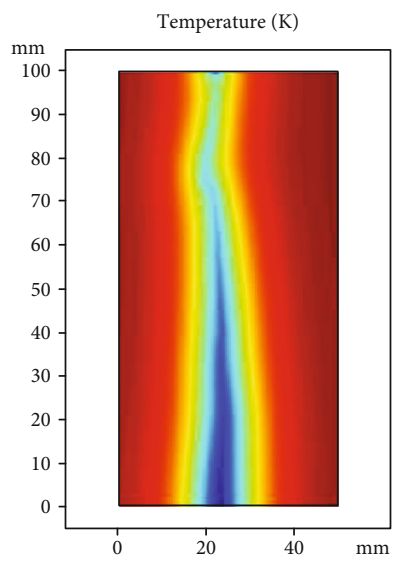

(e) Water injection at $433 \mathrm{~K}$

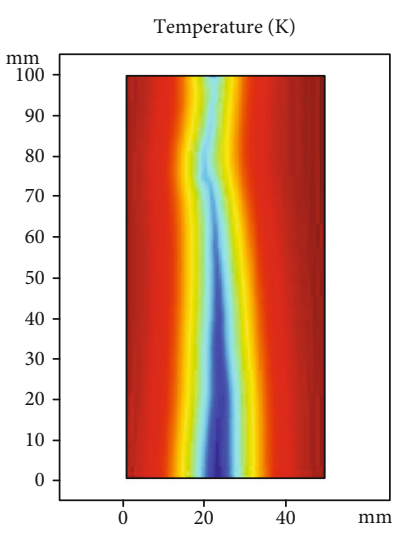

(b) $\mathrm{CO}_{2}$ injection at $373 \mathrm{~K}$

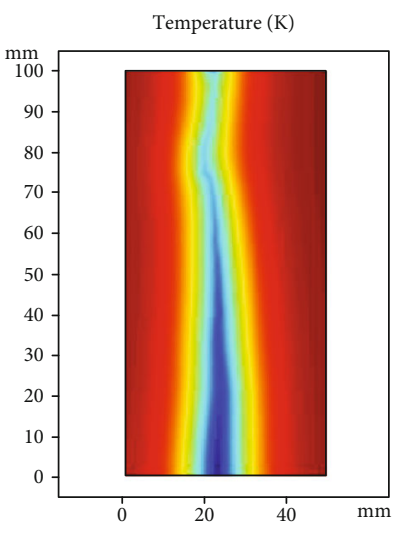

(f) $\mathrm{CO}_{2}$ injection at $433 \mathrm{~K}$

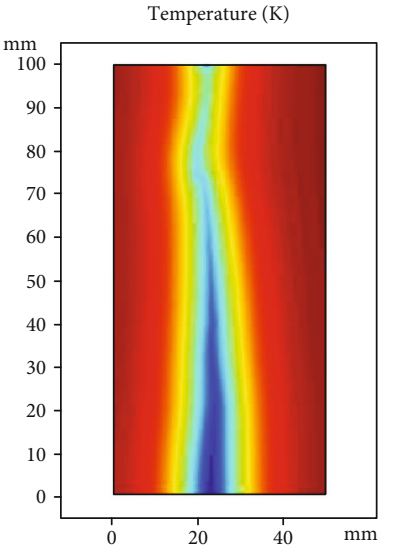

(c) Water injection at $403 \mathrm{~K}$ initial

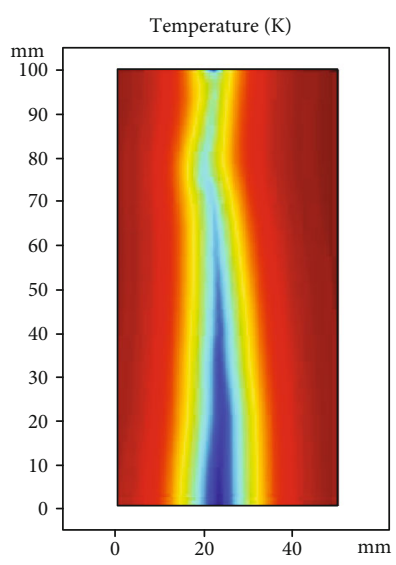

(g) Water injection at $493 \mathrm{~K}$

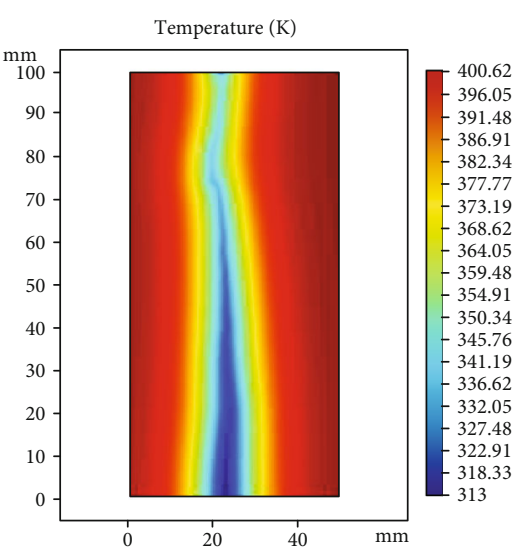

(d) $\mathrm{CO}_{2}$ injection at $403 \mathrm{~K}$

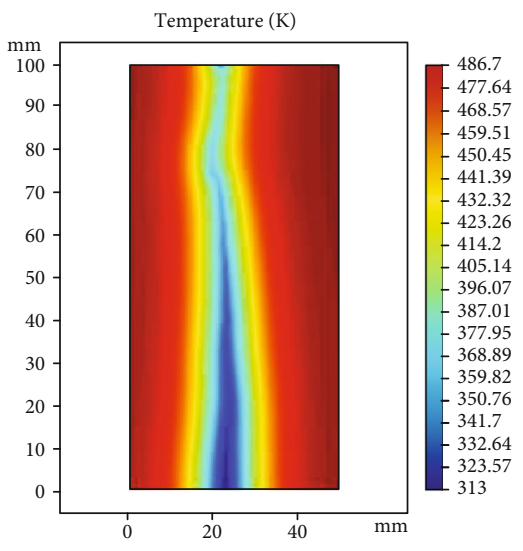

(h) $\mathrm{CO}_{2}$ injection at $493 \mathrm{~K}$

FIGURE 14: Temperature distribution after fluid injection at different initial temperatures.

fracture surface decreases rapidly after fluid injection, resulting in the rapid decrease of initial net heat. In the actual EGS reservoir, the heat recovery area will be compensated by the nearby high-temperature rock mass. When boundary heat source is added to the model, the net heat curve fluctuates slightly, which is the result of the interaction between heat recovery and heat compensation. Figures 12 and 13 show the stress distribution of rock samples after $600 \mathrm{~s}$ water injection and $600 \mathrm{~s} \mathrm{CO}_{2}$ injection at the initial temperature of $373 \mathrm{~K}-493 \mathrm{~K}$, respectively. It can be seen that when the initial temperature increases, the internal stress of the model increases. Generally, the density viscosity ratio of $\mathrm{CO}_{2}$ is larger than that of water, and the sensitivity of the two fluids to temperature and pressure is quite different. This ratio of water is mainly a function of temperature and less affected by pressure. However, for $\mathrm{CO}_{2}$, this ratio is significantly affected by temperature and pressure. When the temperature of rock sample increases from $373 \mathrm{~K}$ to $493 \mathrm{~K}$, the density viscosity ratio of water increases by 0.5 , and the specific enthalpy increases by $120 \mathrm{~kJ} / \mathrm{kg}$, and the net heat of water increases with the increase of rock temperature. However, the above changes in the rock sample temperature decrease the density viscosity ratio of $\mathrm{CO}_{2}$ by 1 and increase the specific enthalpy by only $30 \mathrm{~kJ} / \mathrm{kg}$. The former

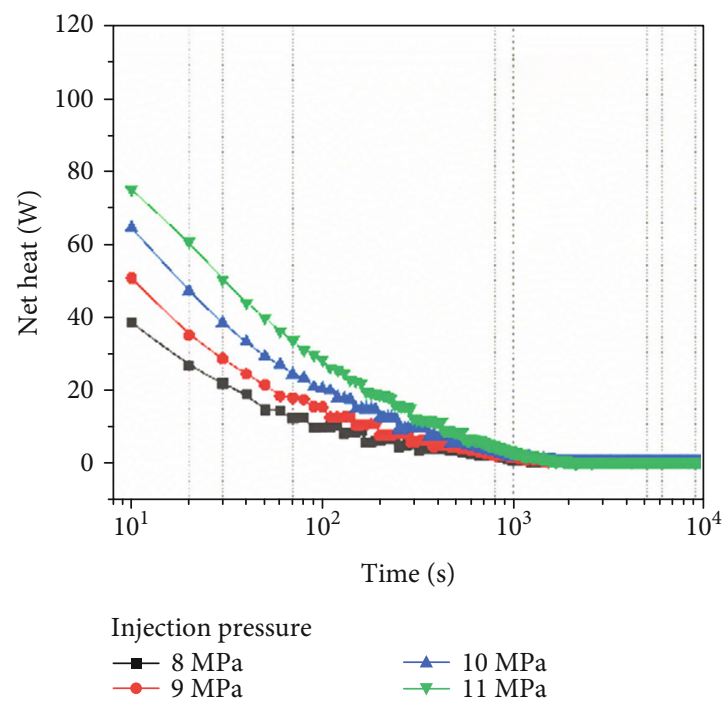

Figure 15: Change of net heat with $\mathrm{CO}_{2}$ injection time at different injection pressures.

plays a leading role in the influence of the net heat, while the net heat of $\mathrm{CO}_{2}$ decreases with the increase of rock temperature. 


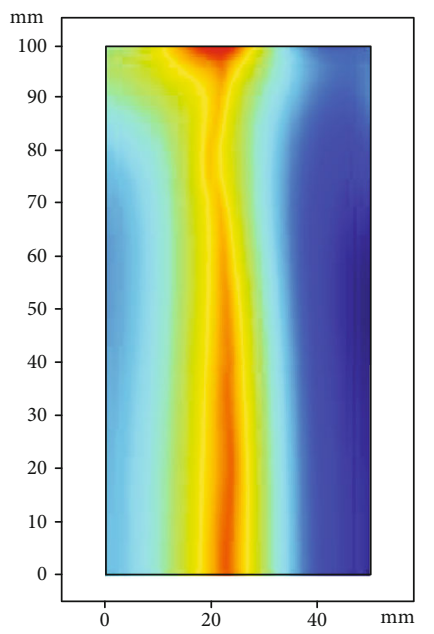

(a) $8 \mathrm{MPa}$

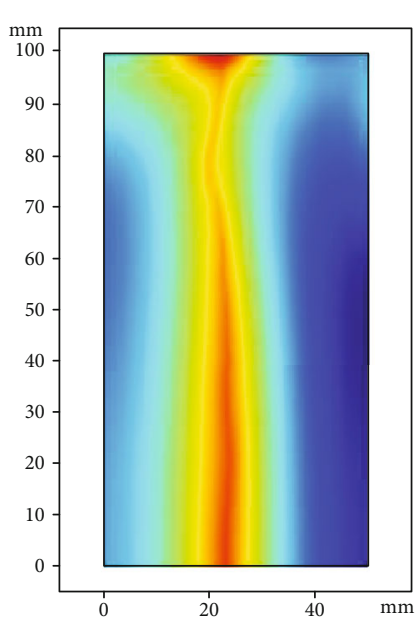

(b) $9 \mathrm{MPa}$

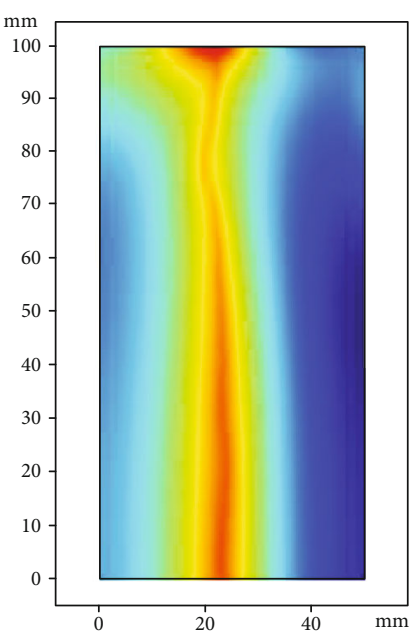

(c) $10 \mathrm{MPa}$

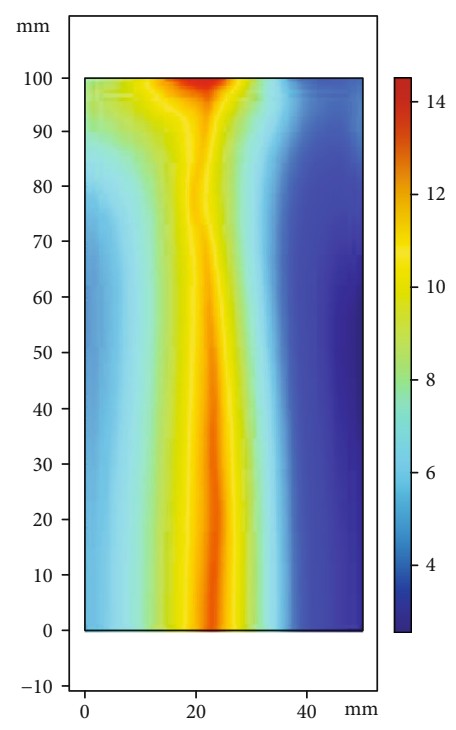

(d) $11 \mathrm{MPa}$

FIgURE 16: Stress distribution after $600 \mathrm{~s} \mathrm{CO}_{2}$ injection under different injection pressures.

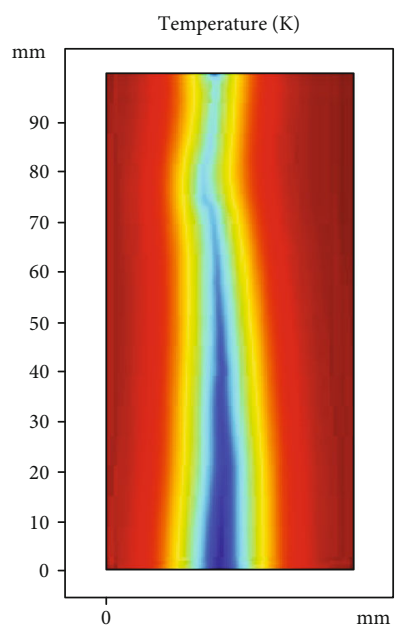

(a) $8 \mathrm{MPa}$ injection

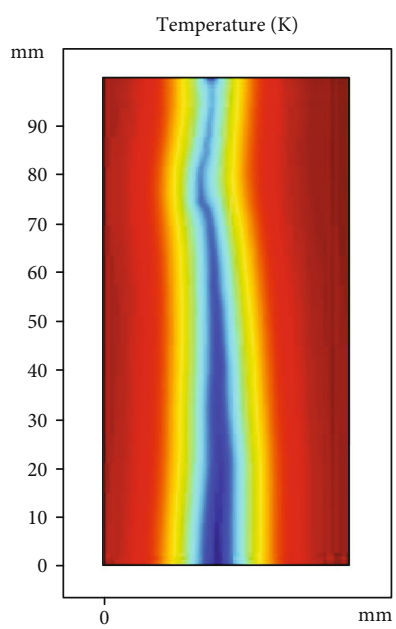

(b) $9 \mathrm{MPa}$ injection

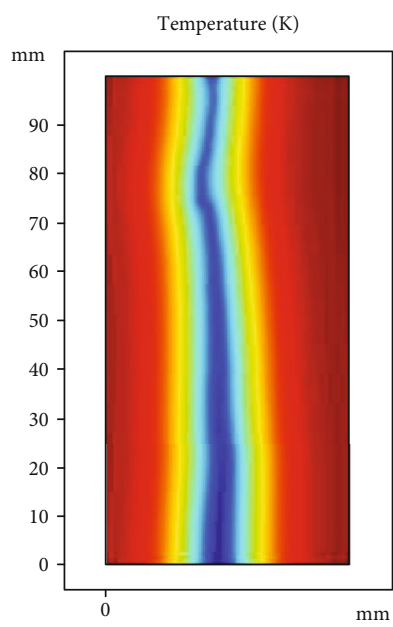

(c) $10 \mathrm{MPa}$ injection

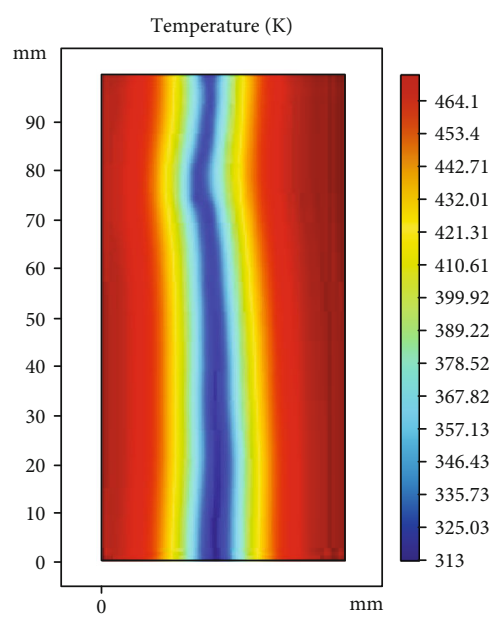

(d) $11 \mathrm{MPa}$ injection

Figure 17: Temperature distribution after $\mathrm{CO}_{2}$ injection at different injection pressures.

Figure 14 shows the temperature distribution characteristics of rock samples after water injection and $\mathrm{CO}_{2}$ injection for $600 \mathrm{~s}$ at $373-493 \mathrm{~K}$ initial temperature. It can be seen that the heat loss of rock sample after $\mathrm{CO}_{2}$ injection is slightly higher than that of water injection under the same initial temperature of rock sample. This is consistent with the results of the influence of confining pressure. Therefore, the thermal recovery efficiency of $\mathrm{CO}_{2}$ can be higher than that of water by reasonably selecting the injection conditions of $\mathrm{CO}_{2}$.

4.3. Effect of Injection Pressure. In the simulation of factors affecting $\mathrm{CO}_{2}$ injection pressure, the initial temperature of rock sample is $473 \mathrm{~K}$, the boundary heat source is $0.001 \mathrm{~W} / \mathrm{mm}^{2}$, axial pressure is $35 \mathrm{MPa}$, and the confining pressure is $26 \mathrm{MPa}$. The model simulates the thermal recovery process of $\mathrm{CO}_{2}$ under high injection pressure of $8 \mathrm{MPa}$, $9 \mathrm{MPa}, 10 \mathrm{MPa}$, and $11 \mathrm{MPa}$, respectively. Figure 15 shows the rule of net heat variation with $\mathrm{CO}_{2}$ injection time under different injection pressures.

It is found that the net heat extracted by $\mathrm{CO}_{2}$ increases with the increase of injection pressure in the same amount of time. Comparing with the previous experimental research, the results are generally consistent with the experimental results [37]. The increase of gas injection pressure leads to the increase of gas volume flow in unit time and the heat exchange of gas in rock fracture. The increase of gas injection pressure leads to the increase of rock permeability, resulting in the increase of $\mathrm{CO}_{2}$ mass flow rate at the outflow end. At the same time, it also reduces the heat exchange time 
of $\mathrm{CO}_{2}$ in fracture. Under the combined influence of the two factors, the net heat increases with the increase of injection pressure, which indicates that the mass flow rate plays a leading role.

Figure 16 shows the stress distribution of rock sample after $\mathrm{CO}_{2}$ injection for $600 \mathrm{~s}$ under different injection pressures. It can be seen that the increase of $\mathrm{CO}_{2}$ injection pressure has little effect on the internal stress of the model, and the crack opening will not change much. Compared with the effect of $\mathrm{CO}_{2}$ mass flow rate increasing, the effect of stress can be neglected.

The temperature distribution of rock sample after $\mathrm{CO}_{2}$ injection for $600 \mathrm{~s}$ under different injection pressures is shown in Figure 17. It can be found that the heat loss of rock sample gradually increases with the increase of injection pressure in a certain period of time. Therefore, increasing the injection pressure of the fluid is beneficial to the thermal recovery of EGS, but suppresses the thermal compensation effect, and significantly reduces the production life of the reservoir.

\section{Conclusions}

In this paper, a numerical model is established to simulate the influence of confining pressure and initial temperature of rock sample on the thermal recovery rate during water injection and $\mathrm{CO}_{2}$ injection of fractured rock sample, and the influence of $\mathrm{CO}_{2}$ injection pressure on the thermal recovery rate. This paper compares and analyzes the advantages of heat recovery by water injection and $\mathrm{CO}_{2}$ injection and obtains the following main conclusions:

(1) After water injection (or $\mathrm{CO}_{2}$ ), the temperature at the measuring point increases with the increase of confining pressure, and there are three stages of temperature change: initial stable stage, rapid decrease stage, and final stable stage. After thermal recovery by water injection, the temperature of the measuring point is slightly higher than that of $\mathrm{CO}_{2}$ injection, especially under the confining pressure of $35 \mathrm{MPa}$. The temperature difference of the measuring point between the two conditions in the third stage is about $10 \mathrm{~K}$. The net heat decreases with the increase of confining pressure, and under the same confining pressure, the net heat extracted after water injection is slightly higher than that of $\mathrm{CO}_{2}$ injection. This difference is not obvious under low confining pressure, but with the increase of confining pressure, the thermal recovery efficiency of water is significantly higher than that of $\mathrm{CO}_{2}$

(2) The net heat of water increases with the increase of rock sample temperature, while the net heat of $\mathrm{CO}_{2}$ decreases with the increase of rock sample temperature. At the temperature of $393 \mathrm{~K}$ rock sample, the maximum net heat ratio of $\mathrm{CO}_{2}$ to water is about 3 . With the increase of sample temperature, the maximum net heat ratio of $\mathrm{CO}_{2}$ to water decreases to 0.4 at $493 \mathrm{~K}$. Therefore, with the increase of rock tem- perature, the heat extraction rate of $\mathrm{CO}_{2}$ is gradually lower than that of water

(3) In the same amount of time, the net heat extracted by $\mathrm{CO}_{2}$ increases with the increase of injection pressure. With the increase of injection pressure, the velocity of $\mathrm{CO}_{2}$ in fracture increases, which increases the mass flow rate of $\mathrm{CO}_{2}$, but also reduces the heat exchange time of $\mathrm{CO}_{2}$ in fracture. The net heat increases with the increase of injection pressure, which indicates that the mass flow rate plays a leading role; increasing the injection pressure of the fluid is beneficial to the thermal recovery of EGS, but suppresses the thermal compensation effect and significantly reduces the production life of the reservoir

\section{Data Availability}

The data used to support the findings of this study are available from the corresponding author upon request.

\section{Conflicts of Interest}

The authors declare that there is no conflict of interest regarding the publication of this paper.

\section{Acknowledgments}

This work was supported by the Fundamental Research Funds for the Central Universities, China University of Mining and Technology (grant number 2015XKZD06).

\section{References}

[1] T. Kober, H. W. Schiffer, M. Densing, and E. Panos, “Global energy perspectives to 2060 - WEC's World Energy Scenarios 2019," Energy Strategy Reviews, vol. 31, p. 100523, 2020.

[2] F. Zeng, W. Wang, Y. Wu, M. Zeng, and W. Li, "Effects of fossil fuel combustion outcome on air environmental quality and study situation," Journal of Minzu University of China, no. 2, pp. 113-120, 2001.

[3] G. L. Wang, W. Zhang, J. Y. Liang, W. J. Lin, Z. M. Liu, and W. L. Wang, "Evaluation of geothermal resources potential in China," Acta Geoscientia Sinica, vol. 38, no. 4, pp. 448459, 2017.

[4] T. Xu, Y. Zhang, Z. Zeng, and X. Bao, "Technology progress in an enhanced geothermal system (hot dry rock)," Science Technology Review, vol. 30, no. 32, pp. 42-45, 2012.

[5] W. Li, X. Kong, L. Yuan et al., "General situation and suggestions of development and utilization of geothermal resources in China," China Mining Magazine, vol. 29, pp. 22-26, 2020.

[6] T. F. Xu, Y. L. Yuan, Z. J. Jiang, Z. Hou, and B. Feng, "Hot dry rock and geothermal engineering: international experience and China prospect," Journal of Jilin University, vol. 46, no. 4, pp. 1139-1152, 2016.

[7] D. L. Gallup, "Production engineering in geothermal technology: a review," Geothermics, vol. 38, no. 3, pp. 326-334, 2009.

[8] Y. Zhao, Z. Feng, B. Xi, Z. Wan, D. Yang, and W. Liang, "Deformation and instability failure of borehole at high temperature and high pressure in hot dry rock exploitation," Renewable Energy, vol. 77, pp. 159-165, 2015. 
[9] W. Bujakowski, A. Barbacki, M. Miecznik, L. Pająk, R. Skrzypczak, and A. Sowiżdżał, "Modelling geothermal and operating parameters of EGS installations in the Lower Triassic sedimentary formations of the central Poland area," Renewable Energy, vol. 80, pp. 441-453, 2015.

[10] X. Song, Y. Shi, G. Li et al., "Numerical simulation of wellborereservoir coupling in enhanced geothermal system," Renewable Energy Resources, vol. 33, no. 3, pp. 421-428, 2018.

[11] Z. Ye, M. Janis, A. Ghassemi, and S. Bauer, "Experimental investigation of injection-driven shear slip and permeability evolution in granite for EGS stimulation," in Proceedings 42nd Workshop on Geothermal Reservoir Engineering, Stanford University, pp. 13-15, Stanford, California, 2017.

[12] J. W. Pritchett, "On the relative effectiveness of $\mathrm{H}_{2} \mathrm{O}$ and $\mathrm{CO}_{2}$ as reservoir working fluids for EGS heat mining," Transactions - Geothermal Resources Council, vol. 33, pp. 235-239, 2009.

[13] J. B. Randolph and M. O. Saar, "Combining geothermal energy capture with geologic carbon dioxide sequestration," Geophysical Research Letters, vol. 38, no. 10, 2011.

[14] K. Pruess and M. Azaroual, "On the feasibility of using supercritical $\mathrm{CO}_{2}$ as heat transmission fluid in an engineered hot dry rock geothermal system [J]," in Proceedings of the Thirty-First Workshop on Geothermal Reservoir Engineering, pp. 386-393, 2006.

[15] F. Zhang, P. Jiang, and R. Xu, "System thermodynamic performance comparison of $\mathrm{CO}_{2}$-EGS and water-EGS systems," Applied Thermal Engineering, vol. 61, no. 2, pp. 236-244, 2013.

[16] A. D. Atrens, H. Gurgenci, and V. Rudolph, " $\mathrm{CO}_{2}$ thermosiphon for competitive geothermal power generation," Energy \& Fuels, vol. 23, no. 1, pp. 553-557, 2009.

[17] H. Abé, D. V. Duchane, R. H. Parker, and M. Kuriyagawa, "Present status and remaining problems of HDR/HWR system design," Geothermics, vol. 28, no. 4-5, pp. 573-590, 1999.

[18] P. Olasolo, M. C. Juárez, M. P. Morales, S. D'Amico, and I. A. Liarte, "Enhanced geothermal systems (EGS): a review," Renewable and Sustainable Energy Reviews, vol. 56, pp. 133144, 2016.

[19] K. Pruess, "On production behavior of enhanced geothermal systems with $\mathrm{CO}_{2}$ as working fluid," Energy Conversion and Management, vol. 49, no. 6, pp. 1446-1454, 2008.

[20] A. Atrens, H. Gurgenci, and V. Rudolph, "Exergy analysis of a $\mathrm{CO}_{2}$ thermosiphon," in Proceedings, Thirty-Fourth Workshop on Geothermal Reservoir Engineering Stanford University, Stanford, California, 2009.

[21] A. D. Atrens, H. Gurgenci, and V. Rudolph, "Electricity generation using a carbon-dioxide thermosiphon," Geothermics, vol. 39, no. 2, pp. 161-169, 2010.

[22] A. Ram Mohan, U. Turaga, V. Shembekar, D. Elsworth, and S. V. Pisupati, "Utilization of carbon dioxide from coal-based power plants as a heat transfer fluid for electricity generation in enhanced geothermal systems (EGS)," Energy, vol. 57, pp. 505-512, 2013.

[23] Y. He, B. Bai, and X. Li, "Comparative investigation on the heat transfer characteristics of gaseous $\mathrm{CO}_{2}$ and gaseous water flowing through a single granite fracture," International Journal of Thermophysics, vol. 38, no. 11, 2017.

[24] C. L. Wang, W. L. Cheng, Y. L. Nian, L. Yang, B. B. Han, and M. H. Liu, "Simulation of heat extraction from $\mathrm{CO}_{2}$-based enhanced geothermal systems considering $\mathrm{CO}_{2}$ sequestration," Energy, vol. 142, pp. 157-167, 2018.
[25] F. Z. Zhang, R. N. Xu, and P. X. Jiang, "Thermodynamic analysis of enhanced geothermal systems using impure $\mathrm{CO}_{2}$ as the geofluid," Applied Thermal Engineering, vol. 99, pp. 1277$1285,2016$.

[26] F. Wang and N. A. Jin, "The impacts of different $\mathrm{CO}_{2}$ injection temperatures on heat extraction rate in $\mathrm{CO}_{2}$ enhanced geothermal system: based on the CCS demonstration project in Erdos," Science \& Technology Review, vol. 31, 2013.

[27] F. Luo, R.-N. Xu, and P.-X. Jiang, "Numerical investigation of fluid flow and heat transfer in a doublet enhanced geothermal system with $\mathrm{CO}_{2}$ as the working fluid ( $\mathrm{CO}_{2}$-EGS)," Energy, vol. 64 , pp. 307-322, 2014.

[28] K. Pruess, "Role of Fluid Pressure in the Production Behavior of Enhanced Geothermal Systems with $\mathrm{CO} 2$ as Working Fluid[J]," American Journal of Respiratory \& Critical Care Medicine, vol. 189, no. 189, pp. 369-370, 2008.

[29] M. A. Biot, "Theory of propagation of elastic waves in a fluidsaturated porous solid. I. Low frequency range. II. Higher frequency range," The Journal of the Acoustical Society of America, vol. 28, no. 182, pp. 168-191, 1955.

[30] K. V. Terzaghi, “Die Berechnung der Durchassigkeitsziffer des Tones aus dem Verlauf der hydrodynamischen Spannungserscheinungen [J]," Akademie der Wissenschaften in Wien. Sitzungsberichte, vol. 11, pp. 105-124, 1923.

[31] P. Xiao, F. Yan, B. Dou, H. Tian, H. Liu, and Z. Zhu, "Numerical simulation of parallel multi fracture heat transfer process in horizontal wells of enhanced geothermal system," Renewable Energy Resources, vol. 37, no. 7, pp. 1091-1099, 2020.

[32] Z. Dianji, B. Shiwei, and Y. Chunhe, "Analysis and study on permeability of fractured rock mass," Site Investigation Science and Technology, vol. 1, pp. 24-27, 2003.

[33] L. Pan, "Study on effect of thermo-hydro-mechanical-chemical coupling in $\mathrm{CO}_{2}$-EGS of hot dry rock," 2020.

[34] Z. Qu, W. Zhang, and T. K. Guo, "Influence of different fracture morphology on heat mining performance of enhanced geothermal systems based on COMSOL," International Journal of Hydrogen Energy, vol. 42, no. 29, pp. 18263-18278, 2017.

[35] B. Shu, R. Zhu, D. Elsworth et al., "Effect of temperature and confining pressure on the evolution of hydraulic and heat transfer properties of geothermal fracture in granite," Applied Energy, vol. 272, p. 115290, 2020.

[36] P. Li, Y. Wu, J. Luo, and H. Zhang, "Effects of $\mathrm{CO}_{2}$ thermal properties and local fracture heterogeneity on heat transfer by supercritical $\mathrm{CO}_{2}$ flowing through fractured granite," Energy Reports, vol. 7, pp. 1875-1887, 2021.

[37] P. Li, Y. Wu, J. Liu et al., "Effects of injection parameters on heat extraction performance of supercritical $\mathrm{CO}_{2}$ in enhanced geothermal systems," Energy Science and Engineering, vol. 7, no. 6, pp. 3076-3094, 2019. 